\title{
The Importance of Charge Redistribution during Electrochemical Reactions: A Density Functional Theory Study of Silver Orthophosphate $\left(\mathrm{Ag}_{3} \mathrm{PO}_{4}\right)$
}

\author{
Xi Cao ${ }^{1}$, Xueqing Zhang ${ }^{2,3 *}$, Rochan Sinha $^{2}$, Shuxia Tao ${ }^{1 *}$, Anja Bieberle-Hütter ${ }^{2,3 *}$ \\ 1. Center for Computational Energy Research, Department of Applied Physics, Eindhoven University of Technology, \\ P.O. Box 513, 5600MB, Eindhoven, The Netherlands.
}

2. Electrochemical Materials and Interfaces, Dutch Institute for Fundamental Energy Research (DIFFER), De Zaale 20, 5612AJ, Eindhoven, The Netherlands.

3. Center for Computational Energy Research, Dutch Institute for Fundamental Energy Research (DIFFER), De Zaale 20, 5612AJ, Eindhoven, The Netherlands.

\begin{abstract}
The structural sensitivity of silver orthophosphate $\left(\mathrm{Ag}_{3} \mathrm{PO}_{4}\right)$ for photoelectrochemical water oxidation on (100), (110) and (111) surfaces has recently been reported by experimental studies (Martin et al. 2013). The (111) surface showed the highest performance with an oxygen evolution rate of 10 times higher than the other surfaces. The high performance of the (111) surface was attributed to high hole mobility, high surface energy and, in a recent theoretical study (Ma et al. 2017), to a lower $\mathrm{OH}$ adsorption energy and the band structure. The investigations are based on a few structures and a full atomistic picture of the $\mathrm{Ag}_{3} \mathrm{PO}_{4}$ under electrochemical reactions is still missing. Therefore, we report here a systematic study of the oxygen evolution reaction (OER) of $\mathrm{Ag}_{3} \mathrm{PO}_{4}$ (100), (110), and (111) surfaces by density functional theory (DFT) calculations. Through a detailed investigation of the reaction energies and the overpotentials of OER on all possible surface orientations with all possible terminations and different involvement of Ag adsorption sites, we can confirm that (111) surfaces are highly active. However, surface orientation was not found to exclusively determine the electrochemical activity; neither did the number of $\mathrm{Ag}$ atoms involved in the adsorption of the intermediate species nor the type of surface termination or the different potential determining reaction steps. By using Bader charge analysis and investigation of the charge redistribution during OER, we found that the highest activity, i.e. lowest overpotential, is related to the charge redistribution of two OER steps, namely the $\mathrm{O}_{\mathrm{ad}}$ and the $\mathrm{HOO}_{\mathrm{ad}}$ formation. If the charge redistribution between these steps is small, then the overpotential is small and, hence, the activity is high. Charge redistributions are usually small for the (111) surface and therefore the (111) surface is usually the most active one. The concept of charge redistribution being decisive for the high activity of $\mathrm{Ag}_{3} \mathrm{PO}_{4}$ may open a new design strategy for materials with highly efficient electrochemical surfaces.
\end{abstract}

*Corresponding authors.

E-mail address: X.Zhang@differ.nl (X. Zhang)

E-mail address: A.Bieberle@differ.nl (A. Bieberle-Hütter)

E-mail address: S.X.Tao@tue.nl (S. Tao) 


\section{Introduction}

Photoelectrochemical (PEC) solar fuel production has the potential to provide an eco-friendly and renewable alternative to fossil fuels in order to solve two worldwide problems: the shortage of usable energy and the increasing amount of greenhouse emissions ${ }^{[1-3]}$. In PEC solar fuel production, the solar energy directly converts water or $\mathrm{CO}_{2}$ into a fuel, such as hydrogen, through electrochemical reactions and electrochemically active materials. The efficiency is determined by four fundamental processes: light absorption, separation of electrons and holes, migration of charge towards the surface, and the electrochemical reactions ${ }^{[4]}$. Regarding the electrochemical reactions, the oxygen evolution reaction (OER) is known as the main bottleneck related to a 4-electron process ${ }^{[5-6]}$.

Silver Orthophosphate $\left(\mathrm{Ag}_{3} \mathrm{PO}_{4}\right)$ is a promising candidate for OER due to its appropriate band gap $\left(2.36 \mathrm{eV}^{[7]}\right)$, non-toxicity, and high photocatalytic activity ${ }^{[8-10]}$. However, the poor photostability and difficulties in the control of crystal size and morphology limit its practical application ${ }^{[6]}$. The high OER activity of $\mathrm{Ag}_{3} \mathrm{PO}_{4}$ was initially discovered by $\mathrm{O}_{2}$ evolution and organic dye decomposition experiments. It was shown that the performance of $\mathrm{Ag}_{3} \mathrm{PO}_{4}$ is more than 10 times higher than that of $\mathrm{BiVO}_{4}$ and $\mathrm{TiO}_{2-\mathrm{x}} \mathrm{N}_{\mathrm{x}}{ }^{[7]}$. Recently, several groups investigated the application of the $\mathrm{Ag}_{3} \mathrm{PO}_{4}$ for water splitting and found high electrochemical activity ${ }^{[10-12]}$. Zheng et al. found by comparing the degradation of positively charged metheylene blue, methyl orange, and rhodamine $\mathrm{B}$ that the (111) surface of $\mathrm{Ag}_{3} \mathrm{PO}_{4}$ has the highest photocatalytic activity among (100), (110), and (111) surfaces ${ }^{[11]}$.

Martin et al. ${ }^{[10]}$ demonstrated in a combined experimental and computational study extraordinary structural sensitivity of $\mathrm{Ag}_{3} \mathrm{PO}_{4}$. The activity for OER on the (111) surface was found to be nearly 10 times larger than that on the (100) and (110) surface, respectively. The extremely high activity of the (111) surface was attributed to the stability of the surface (highest surface formation energy for (111) surface) and its electronic properties (high mobility of holes) ${ }^{[10]}$. Several other ab-initio studies using DFT are also devoted to the thermal stability and the electronic properties of the bulk and different surfaces ${ }^{[7,10,13-15]}$. Using various levels of approximations, i.e. standard DFT ${ }^{[7]}, \mathrm{DFT}+\mathrm{U}^{[10,13]}$, hybrid methods ${ }^{[14,15]}$, most results pointed to similar conclusions as Martin et al. regardless of the degree of accuracy. Ma et al. ${ }^{[16]}$ demonstrated the surface dependence of electronic structures of $\mathrm{Ag}_{3} \mathrm{PO}_{4}$ and explained the better performance of the (111) surface compared to the (110) and (100) surfaces by an absence of mid-gap states. Similar tunable band edge energies via surface engineering were previously reported for other water oxidation photocatalysts as well, such as $\mathrm{NiOOH}^{[17]}$ and $\mathrm{CdSe}^{[18]}$. In addition, Ma et al. ${ }^{[16]}$ found that the much lower adsorption energy of $\mathrm{HO}^{*}$ on the (111) surface leads to the deprotonation of the first absorbed water molecule becoming a favorable step at the (111) surface compared to (100) and (110). However, the study is based on three structures only and different adsorption sites ( $\mathrm{Ag}$ and $\mathrm{P}$ ); the lowest overpotential was found for adsorption on an Ag site. A systematic atomistic analysis of the electrochemical activity has not been reported yet. This is, however, necessary in order to explain why the (111) surface is more active than other surfaces.

In this study, we therefore explore the electrochemical activity of $\mathrm{Ag}_{3} \mathrm{PO}_{4}$ by evaluating the overpotentials and the potential determining steps of OER by DFT. Through an extensive investigation of the overpotentials of OER on (100), (110), and (111) surfaces with all possible terminations and different involvement of $\mathrm{Ag}$ adsorption sites, we confirm the structural 
sensitivity of the electrochemical activities, can, however, not conclusively relate the structure and the electrochemical activity. Using Bader charge analysis, we demonstrate the correlation between charge distribution, overpotential, and potential determining steps of OER on $\mathrm{Ag}_{3} \mathrm{PO}_{4}$ and reveal the reasons for different electrochemical activities of different structures.

\section{Computational details}

Many reaction mechanisms of the OER on metal oxide surfaces were proposed in the literature as discussed in a recent review paper by Zhang and Bieberle-Hütter ${ }^{[19]}$. Here, we consider the mechanism proposed by Rossmeisl et al. ${ }^{[20]}$. This mechanism has been proven to be successful in predicting trends in overpotentials of OER at many oxide systems ${ }^{[3,21-29]}$. The mechanism consists of the following four proton-coupled electron transfer (PCET) steps and is also illustrated in Figure 1. It is assumed that all intermediate species adsorb on Ag sites, since metal sites are usually the active adsorption sites ${ }^{[30,31]}$.

$$
\begin{aligned}
& \mathrm{H}_{2} \mathrm{O}+\mathrm{ad} \rightarrow \mathrm{HO}_{\mathrm{ad}}+\mathrm{H}^{+}+\mathrm{e}^{-} \\
& \mathrm{HO}_{\mathrm{ad}} \rightarrow \mathrm{O}_{\mathrm{ad}}+\mathrm{H}^{+}+\mathrm{e}^{-} \\
& \mathrm{H}_{2} \mathrm{O}+\mathrm{O}_{\mathrm{ad}} \rightarrow \mathrm{HOO}_{\mathrm{ad}}+\mathrm{H}^{+}+\mathrm{e}^{-} \\
& \mathrm{HOO}_{\mathrm{ad}} \rightarrow \mathrm{ad}+\mathrm{O}_{2}+\mathrm{H}^{+}+\mathrm{e}^{-}
\end{aligned}
$$

The free energies of above reactions under an applied potential can be calculated as ${ }^{[20]}$

$$
\begin{aligned}
& \Delta \mathrm{G}_{1}=\mathrm{E}\left(\mathrm{HO}_{\mathrm{ad}}\right)-\mathrm{E}(\mathrm{ad})-\mathrm{E}_{\mathrm{H} 2 \mathrm{O}}+0.5 \mathrm{E}_{\mathrm{H} 2}+\left(\Delta_{\mathrm{ZPE}}-\mathrm{T} \Delta \mathrm{S}\right)_{1}-\mathrm{eU} \\
& \Delta \mathrm{G}_{2}=\mathrm{E}\left(\mathrm{O}_{\mathrm{ad}}\right)-\mathrm{E}\left(\mathrm{HO}_{\mathrm{ad}}\right)+0.5 \mathrm{E}_{\mathrm{H} 2}+\left(\Delta_{\mathrm{ZPE}}-\mathrm{T} \Delta \mathrm{S}\right)_{2}-\mathrm{eU} \\
& \Delta \mathrm{G}_{3}=\mathrm{E}\left(\mathrm{HOO}_{\mathrm{ad}}\right)-\mathrm{E}\left(\mathrm{O}_{\mathrm{ad}}\right)-\mathrm{E}_{\mathrm{H} 2 \mathrm{O}}+0.5 \mathrm{E}_{\mathrm{H} 2}+\left(\Delta_{\mathrm{ZPE}}-\mathrm{T} \Delta \mathrm{S}\right)_{3}-\mathrm{eU} \\
& \Delta \mathrm{G}_{4}=\mathrm{E}(\mathrm{ad})-\mathrm{E}\left(\mathrm{HOO}_{\mathrm{ad}}\right)+\mathrm{E}_{\mathrm{O} 2}+0.5 \mathrm{E}_{\mathrm{H} 2}+\left(\Delta_{\mathrm{ZPE}}+\mathrm{T} \Delta \mathrm{S}\right)_{4}-\mathrm{eU}
\end{aligned}
$$

where $\Delta G_{n}$ are the free energies of the reactions (1) to (4) and $U$ is the electrode potential relative to the standard hydrogen electrode. $\Delta_{\mathrm{ZPE}}$ and $\Delta \mathrm{S}$ are the differences in zero point energy and entropy of the reactants and products in the reactions, respectively. ad denotes a surface site and $\mathrm{O}_{\mathrm{ad}}, \mathrm{OH}_{\mathrm{ad}}$, and $\mathrm{OOH}_{\mathrm{ad}}$ denote species adsorbed on the surface. According to Rossmeisl et al. ${ }^{[20]}$, the influence of the $\mathrm{pH}$ on the free energy can be taken into account by adding the following term: $\Delta \mathrm{G}(\mathrm{pH})=-\mathrm{kT} x \ln \left[\mathrm{H}^{+}\right]$, where $\mathrm{k}$ is the Boltzmann constant. Unless specified otherwise, we adopt in this work $\Delta \mathrm{G}(\mathrm{pH})=0$ assuming a $\mathrm{pH}$ value of 0 .

In the calculations of free energy changes, we use previously reported values used for $\mathrm{Fe}_{2} \mathrm{O}_{3}$ for $\Delta_{\mathrm{ZPE}}-\mathrm{T} \Delta \mathrm{S}^{[32]}$ and keep them constant for different reaction sites, since they were found to vary little for different oxide materials $\left(\mathrm{Fe}_{2} \mathrm{O}_{3}, \mathrm{TiO}_{2}, \mathrm{MnO}: \mathrm{ZnO}\right)$ as well as for different reaction sites (top and bridge sites of $\mathrm{MnO}: \mathrm{ZnO}$ alloys) with a maximum differences of $0.05 \mathrm{eV}^{\text {[33]. The }}$ overpotential $\eta$ for OER is defined as the extra potential needed to drive water splitting compared to the standard potential which is $1.23 \mathrm{~V}$ for water splitting. The overpotential is a measure for the electrochemical activity. It is calculated as follows ${ }^{[20]}$,

$$
\eta=\frac{\max \left[\Delta G_{1}, \Delta G_{2}, \Delta G_{3}, \Delta G_{4}\right]}{e}-1.23
$$




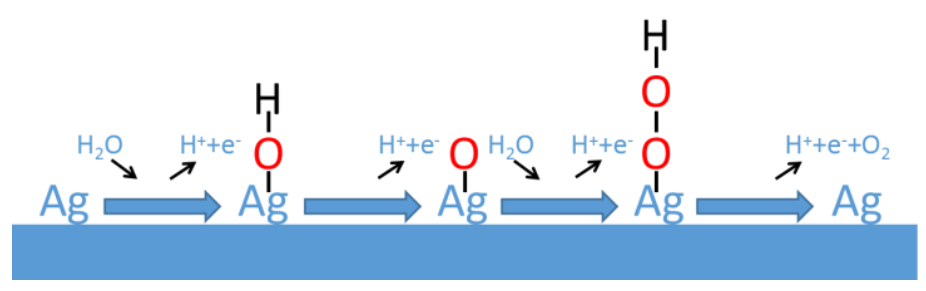

Figure 1. Illustration of the assumed OER mechanism on $\mathrm{Ag}_{3} \mathrm{PO}_{4}$. The adsorption site is $\mathrm{Ag}$.

The free energies of the individual reaction steps were calculated by the DFT using VASP (Vienna Ab initio Simulation Package) ${ }^{[34,35]}$. Projector Augmented Wave potentials ${ }^{[36]}$ were employed with a cut-off energy of $600 \mathrm{eV}$. Perdew-Burke-Ernzerhof functionals ${ }^{[37]}$ were used with $6 \times 6 \times 6 k$-point sampling for bulk and $6 \times 6 \times 1 k$-point sampling for slabs modelling the surfaces with a force threshold of $-0.01 \mathrm{eV} / \AA$ and an energy threshold of $1 \times 10^{-5} \mathrm{eV}$. The optimized lattice parameter of the bulk structure is $6.10 \AA$, which is in well agreement with the experimental result of $6.04 \AA^{[38]}$.

In addition to the energy calculations, we have carried out Bader charge (BC) analysis ${ }^{[39,40]}$ in order to locate the electronic charge density at the interface and the changes during OER. In Bader charge analysis, the total charge (electron density) associated with each atom is determined by using the so-called Bader volume defined by the zero charge flux surfaces. The charge enclosed within this Bader volume is a good approximation of the total electronic charge of an atom. The charge distribution can also be used to determine multipole moments of interacting atoms or molecules.

In our study, we first calculate the Bader charges of all atoms in the bulk $\mathrm{Ag}_{3} \mathrm{PO}_{4}$. The charges of the Ag from the bulk are then compared to the Ag of the surface; it is calculated how these charges change when species are adsorbed on the surface during OER. Next to the Bader charges of the Ag, the Bader charges of the oxygen of the adsorbed oxygen species, i.e. $\mathrm{OH}_{\mathrm{ad}}$, $\mathrm{O}_{\mathrm{ad}}, \mathrm{OOH}_{\mathrm{ad}}$, are calculated. This is used as a measure to compare the bonding strength of different adsorbed species with the Ag atoms. Finally, the charge re-distribution during OER is determined.

\section{Results and Discussion}

\section{Geometries}

Different geometries were modelled using slab models consisting of (1x1) cells in the $x$ and $y$ direction and more than 16 atomic layers (at least three periodic units from bulk structure) with a vacuum reaching $10 \AA$ in the $z$ direction. In total, 6 structures were identified and are summarized in Table 1 and in Figure 2 (unrelaxed structures). A structure is characterized by a surface orientation, namely (100), (110), and (111), and a surface termination. Two terminations were identified for the (100) orientation, three terminations for the (110) orientation, and one termination for the (111) orientation. Per surface termination different $\mathrm{Ag}$ reaction sites can adsorb the intermediate species $\mathrm{OH}_{\mathrm{ad}}, \mathrm{O}_{\mathrm{ad}}$, and $\mathrm{OOH}_{\mathrm{ad}}$. These reaction sites are labelled with capital letters in Table 1 and in Figure 2.

In total, 14 possible geometries are found for the OER on $\mathrm{Ag}_{3} \mathrm{PO}_{4}$. The geometries are labelled as "orientation-termination-index" where index is an increasing number and accounts for the 
different geometries because of different adsorption sites. Taking 111-01-12 as an example, the OERs take place on the (111) surface with termination (01). Figure 3 illustrates the interactions of the intermediates with the $\mathrm{Ag}$ sites for this geometry. The intermediate $\mathrm{OH}_{\mathrm{ad}}$ directly interacts with two $\mathrm{Ag}$ ions (P and Q) (Figure 3a), while the intermediates $\mathrm{O}_{\mathrm{ad}}$ and $\mathrm{OOH}_{\mathrm{ad}}$ interact with three $\mathrm{Ag}$ ions (P, Q, and R) (Figure $3 \mathrm{~b}$ and c, respectively).

Table 1. Summary of all 14 possible geometries for $\mathrm{OER}$ on $\mathrm{Ag}_{3} \mathrm{PO}_{4}$. Each geometry is uniquely labelled as "orientation-termination-index". Capital letters denote different Ag reaction sites. The intermediate species $\mathrm{OH}_{a d}, \mathrm{O}_{a d}, \mathrm{OOH}_{a d}$ can bond to different Ag reaction sites.

\begin{tabular}{ccccccc}
\hline $\begin{array}{c}\text { Structure } \\
1\end{array}$ & Orientation & Termination & Index & $\mathrm{HO}_{\mathrm{ad}}$ & $\mathrm{O}_{\mathrm{ad}}$ & $\mathrm{HOO}_{\mathrm{ad}}$ \\
& 100 & 01 & 1 & $\mathrm{~A}, \mathrm{~B}$ & $\mathrm{~A}, \mathrm{~B}$ & $\mathrm{~A}, \mathrm{~B}$ \\
& 100 & 01 & 2 & $\mathrm{~A}, \mathrm{C}$ & $\mathrm{A}, \mathrm{C}$ & $\mathrm{A}, \mathrm{C}$ \\
\hline 2 & 100 & 02 & 3 & $\mathrm{D}$ & $\mathrm{D}$ & $\mathrm{D}$ \\
& 100 & 02 & 4 & $\mathrm{D}, \mathrm{E}$ & $\mathrm{D}, \mathrm{E}$ & $\mathrm{D}, \mathrm{E}$ \\
\hline 3 & 110 & 01 & 5 & $\mathrm{I}$ & $\mathrm{F}, \mathrm{I}$ & $\mathrm{F}, \mathrm{I}$ \\
& 110 & 01 & 6 & $\mathrm{G}, \mathrm{I}$ & $\mathrm{G}, \mathrm{H}, \mathrm{I}$ & $\mathrm{G}, \mathrm{H}, \mathrm{I}$ \\
& 110 & 01 & 7 & $\mathrm{H}, \mathrm{I}, \mathrm{J}$ & $\mathrm{H}, \mathrm{I}, \mathrm{J}$ & $\mathrm{H}, \mathrm{I}, \mathrm{J}$ \\
\hline 4 & 110 & 02 & 8 & $\mathrm{~K}, \mathrm{~L}$ & $\mathrm{~K}, \mathrm{~L}$ & $\mathrm{~K}, \mathrm{~L}$ \\
& 110 & 02 & 9 & $\mathrm{~K}, \mathrm{~L}$ & $\mathrm{~K}, \mathrm{~L}$ & $\mathrm{~L}$ \\
\hline 5 & 110 & 03 & 10 & $\mathrm{M}, \mathrm{N}$ & $\mathrm{M}, \mathrm{N}$ & $\mathrm{M}, \mathrm{N}$ \\
& 110 & 03 & 11 & $\mathrm{~N}, \mathrm{O}$ & $\mathrm{N}, \mathrm{O}$ & $\mathrm{N}, \mathrm{O}$ \\
\hline 6 & 111 & 01 & 12 & $\mathrm{P}, \mathrm{Q}$ & $\mathrm{P}, \mathrm{Q}, \mathrm{R}$ & $\mathrm{P}, \mathrm{Q}, \mathrm{R}$ \\
& 111 & 01 & 13 & $\mathrm{P}, \mathrm{Q}, \mathrm{R}$ & $\mathrm{P}, \mathrm{Q}, \mathrm{R}$ & $\mathrm{P}, \mathrm{Q}$ \\
& 111 & 01 & 14 & $\mathrm{P}, \mathrm{R}$ & $\mathrm{P}, \mathrm{Q}, \mathrm{R}$ & $\mathrm{P}, \mathrm{Q}, \mathrm{R}$ \\
\hline
\end{tabular}




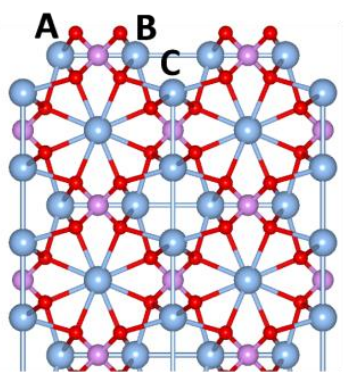

(a) 100-01

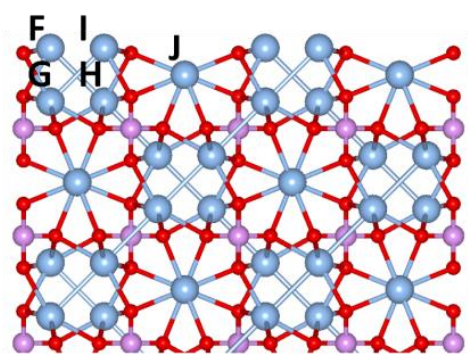

(c) $110-01$

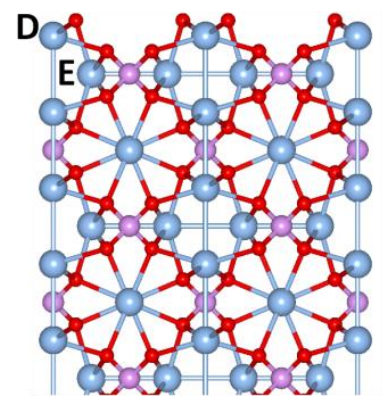

(b) 100-02

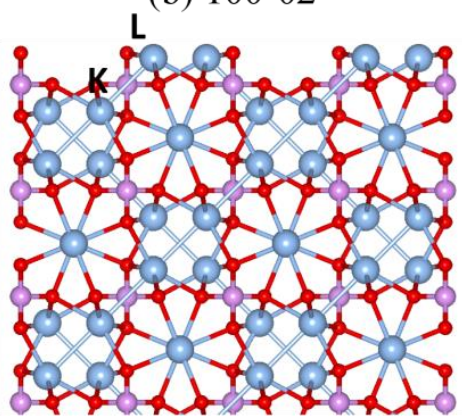

(d) $110-02$
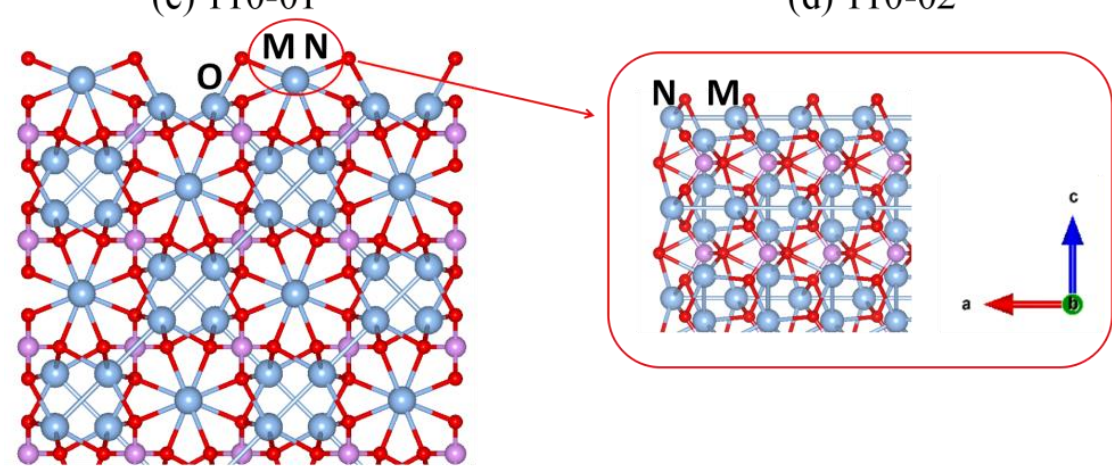

(e) 110-03
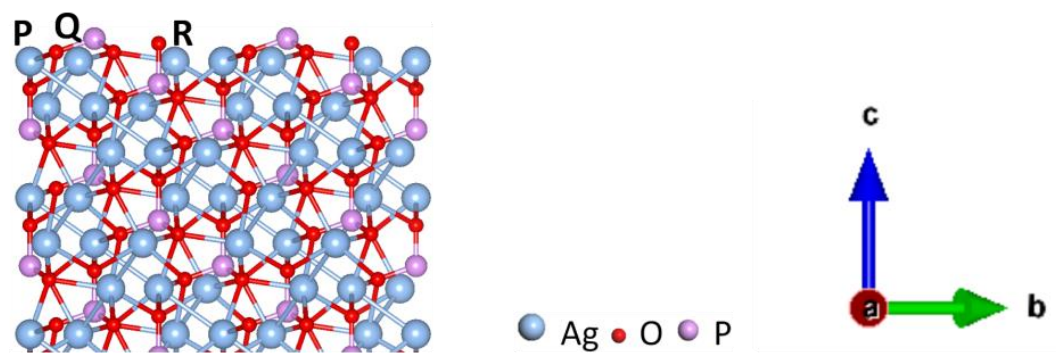

(f) 111-01

Figure 2. Side views (unrelaxed) of the 6 structures including all possible terminations and $A g$ reaction sites: $a$ ) and $b)(100)$ surface; $c)-e)(110)$ surface; $f)(111)$ surface. 01, 02 and 03 denote different types of surface termination (ascending numbering for each surface). Capital letters denote the type of $\mathrm{Ag}$ reaction site. 
a)

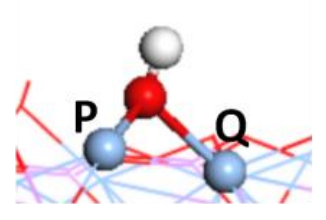

b)

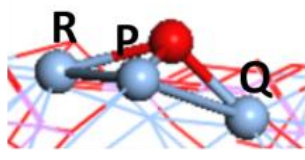

c)

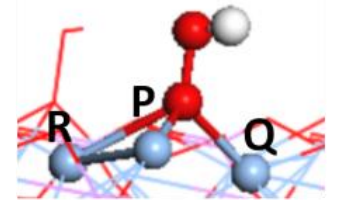

Figure 3. Ag adsorption sites of 111-01-12 interacting with intermediate species: a) two Ag sites interacting with $\mathrm{HO}_{a d}$; b) three $\mathrm{Ag}$ sites interacting with $\mathrm{O}_{a d}$; c) three Ag sites interacting with $\mathrm{HOO}_{a d}$. Capital letters denote the type of Ag reaction site. Colors are the same as in Figure 2.

\section{Overpotentials and their surface sensitivity}

The free energies of all intermediates of the 14 geometries are calculated according to the procedure given in the section Computational Methods. Taking 111-01-12 as example, Figure 4 shows schematically the free energy diagram of the OER. The reaction energies of the four steps are $1.06 \mathrm{eV}, 1.64 \mathrm{eV}, 1.70 \mathrm{eV}$, and $0.52 \mathrm{eV}$, respectively. Without any applied potential ( $\mathrm{U}=0 \mathrm{~V}$, blue curve), the first three steps are uphill and the last step is downhill. This indicates significant potential is needed to drive the overall OER. When applying the water splitting potential of an ideal catalyst, i.e. $1.23 \mathrm{~V}$, the first three steps remain uphill with significantly reduced height (red curve). However, in order to produce $\mathrm{O}_{2}$, all reactions need to be downhill. Therefore, a potential of at least $1.70 \mathrm{~V}$ is required (black curve). The largest step in the OER is the formation of $\mathrm{O}_{\mathrm{ad}}$ (indicated by the red dotted lines). This step is potential determining and results in an overpotential of $0.47 \mathrm{~V}(1.70 \mathrm{~V}-1.23 \mathrm{~V})$.

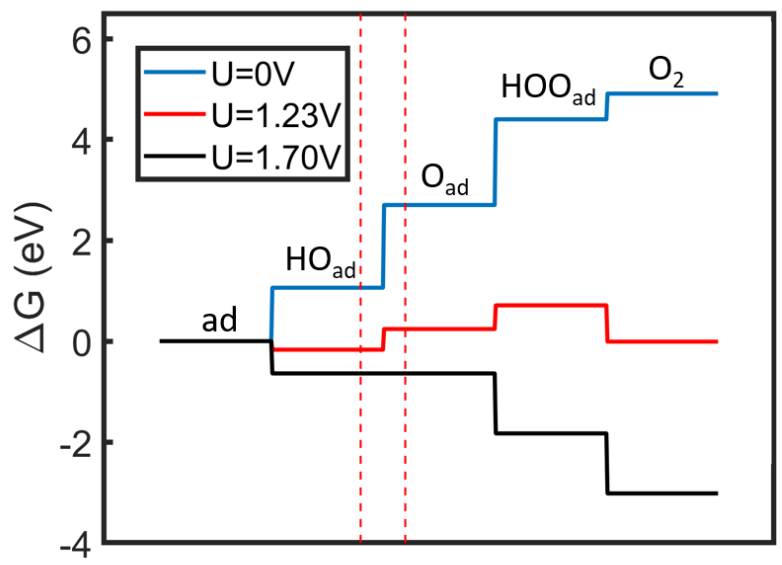

Figure 4. The free energy diagram of OER on 111-01-12 with applied potentials of $0 \mathrm{~V}, 1.23 \mathrm{~V}$ and $1.70 \mathrm{~V}$. The red dotted lines highlight the potential determining step, in this case the $O_{\text {ad }}$ formation. The reaction energies of the four reactions are $1.06 \mathrm{eV}, 1.64 \mathrm{eV}, 1.70 \mathrm{eV}$, and $0.52 \mathrm{eV}$, respectively.

Using the same approach, the overpotentials and the potential determining steps of all 14 geometries were calculated and are summarized in Table 2 and Figure 5. Overpotentials between $0.47 \mathrm{~V}$ and $1.27 \mathrm{~V}$ are found. The overpotential of $0.47 \mathrm{~V}$ is very low for OER on metal oxides. Note that the overpotential of $\mathrm{RuO}_{2}$ whose OER activity is one of the lowest overpotentials known for OER, is only $0.1 \mathrm{eV}$ lower with $0.37 \mathrm{~V}^{[20]}$ compared to the lowest overpotential in this study. 
According to Table 2, different potential determining steps are found for the different geometries. The $\mathrm{O}_{\mathrm{ad}}$ formation and the $\mathrm{HOO}_{\mathrm{ad}}$ formation are usually the potential determining step; there is only one exception, i.e. 110-01-5, were $\mathrm{HO}_{\mathrm{ad}}$ formation is the potential determining step. The last step, i.e. $\mathrm{O}_{2}$ formation from $\mathrm{HOO}_{\mathrm{ad}}$, is never the potential determining step. In Ma et al. ${ }^{[16]}$, the $\mathrm{O}_{\mathrm{ad}}$ formation step is the potential determining step for the three investigated structures.

Figure 5 illustrates the overpotentials of the 14 geometries in form of a bar diagram. A general trend is seen: (111) structures have usually a lower overpotential $(0.51 \mathrm{~V} \pm 0.06 \mathrm{~V})$ compared to the (100) and the (110) structures with average overpotentials of $0.82 \mathrm{~V} \pm 0.34 \mathrm{~V}$ and $0.80 \mathrm{~V}$ $\pm 0.19 \mathrm{~V}$, respectively. These overpotentials compare rather well to Ma et al. [16] who also found the lowest overpotential for adsorption on an $\mathrm{Ag}$ site. It should be mentioned here that the overpotentials calculated in our study all refer to adsorption on Ag sites. In Ma et al. [16], the overpotential for the (111) surface was, in contrast, calculated for the P site which does not allow direct comparison to the results shown here. In principle, $\mathrm{P}$ can also be an adsorption site and also the hydroxylation of $\mathrm{P}$ can impact the electrochemical reaction activities and mechanism. However, using the current simulation cell with hydroxylated $\mathrm{P}$ results in an unrealistic high coverage of the adsorbed hydroxyls. To fully address the effect of hydroxylated $\mathrm{P}$, a larger simulation cell and carefully tuning of the coverage is required; this is planned for a forthcoming study.

This trend of overpotential as a function of the orientation is, however, not fully unambiguous. For example, an overpotential of only $0.49 \mathrm{~V}$ was found for the geometry 100-02-4. We therefore studied the overpotential as a function of the number of Ag atoms involved in the adsorption of the intermediate species, the surface termination, and the potential determining reaction step (Support information Figure S1). However, these analyses did also not result in conclusive relations between the overpotentials and local structure / geometry and rate determining step. In order to elucidate this relation, we carry out Bader charge analysis in the following.

Table 2. Reaction energies $\Delta G_{n}$, overpotentials, and potential determining step of all 14 geometries.

The largest steps are highlighted by bold numbers.

\begin{tabular}{|c|c|c|c|c|c|c|}
\hline Geometry & $\begin{array}{l}\Delta \mathrm{G}_{1} \\
{[\mathrm{eV}]}\end{array}$ & $\begin{array}{l}\Delta \mathrm{G}_{2} \\
{[\mathrm{eV}]}\end{array}$ & $\begin{array}{l}\Delta \mathrm{G}_{3} \\
{[\mathrm{eV}]}\end{array}$ & $\begin{array}{l}\Delta \mathrm{G}_{4} \\
{[\mathrm{eV}]}\end{array}$ & $\begin{array}{l}\text { Overpotential } \\
\text { [V] }\end{array}$ & Potential determining step \\
\hline $100-01-1$ & 1.29 & 2.10 & 1.38 & 0.15 & 0.87 & $\mathrm{O}_{\mathrm{ad}}$ formation $\left(\Delta \mathrm{G}_{2}\right)$ \\
\hline $100-01-2$ & 1.78 & 1.88 & 1.43 & -0.17 & 0.65 & $\mathrm{O}_{\mathrm{ad}}$ formation $\left(\Delta \mathrm{G}_{2}\right)$ \\
\hline $100-02-3$ & 1.71 & 2.50 & 0.61 & 0.09 & 1.27 & $\mathrm{O}_{\mathrm{ad}}$ formation $\left(\Delta \mathrm{G}_{2}\right)$ \\
\hline $100-02-4$ & 1.66 & 1.72 & 1.45 & 0.09 & 0.49 & $\mathrm{O}_{\mathrm{ad}}$ formation $\left(\Delta \mathrm{G}_{2}\right)$ \\
\hline $110-01-5$ & 1.82 & 1.00 & 1.59 & 0.51 & 0.59 & $\mathrm{HO}_{\mathrm{ad}}$ formation $\left(\Delta \mathrm{G}_{1}\right)$ \\
\hline $110-01-6$ & 1.58 & 0.96 & 1.84 & 0.54 & 0.61 & $\mathrm{HOO}_{\mathrm{ad}}$ formation $\left(\Delta \mathrm{G}_{3}\right)$ \\
\hline $110-01-7$ & 0.57 & 1.38 & 2.24 & 0.73 & 1.01 & $\mathrm{HOO}_{\mathrm{ad}}$ formation $\left(\Delta \mathrm{G}_{3}\right)$ \\
\hline $110-02-8$ & 1.78 & 2.01 & 1.14 & -0.01 & 0.78 & $\mathrm{O}_{\mathrm{ad}}$ formation $\left(\Delta \mathrm{G}_{2}\right)$ \\
\hline $110-02-9$ & 2.03 & 2.26 & 0.64 & -0.01 & 1.03 & $\mathrm{O}_{\mathrm{ad}}$ formation $\left(\Delta \mathrm{G}_{2}\right)$ \\
\hline $110-03-10$ & 1.54 & 1.89 & 1.51 & -0.02 & 0.66 & $\mathrm{O}_{\mathrm{ad}}$ formation $\left(\Delta \mathrm{G}_{2}\right)$ \\
\hline $110-03-11$ & 0.91 & 2.13 & 1.27 & 0.61 & 0.90 & $\mathrm{O}_{\mathrm{ad}}$ formation $\left(\Delta \mathrm{G}_{2}\right)$ \\
\hline $111-01-12$ & 1.06 & 1.64 & 1.70 & 0.52 & 0.47 & $\mathrm{HOO}_{\mathrm{ad}}$ formation $\left(\Delta \mathrm{G}_{3}\right)$ \\
\hline 111-01-13 & 1.04 & 1.81 & 1.55 & 0.52 & 0.58 & $\mathrm{O}_{\mathrm{ad}}$ formation $\left(\Delta \mathrm{G}_{2}\right)$ \\
\hline $111-01-14$ & 1.04 & 1.72 & 1.49 & 0.68 & 0.49 & $\mathrm{O}_{\mathrm{ad}}$ formation $\left(\Delta \mathrm{G}_{2}\right)$ \\
\hline
\end{tabular}




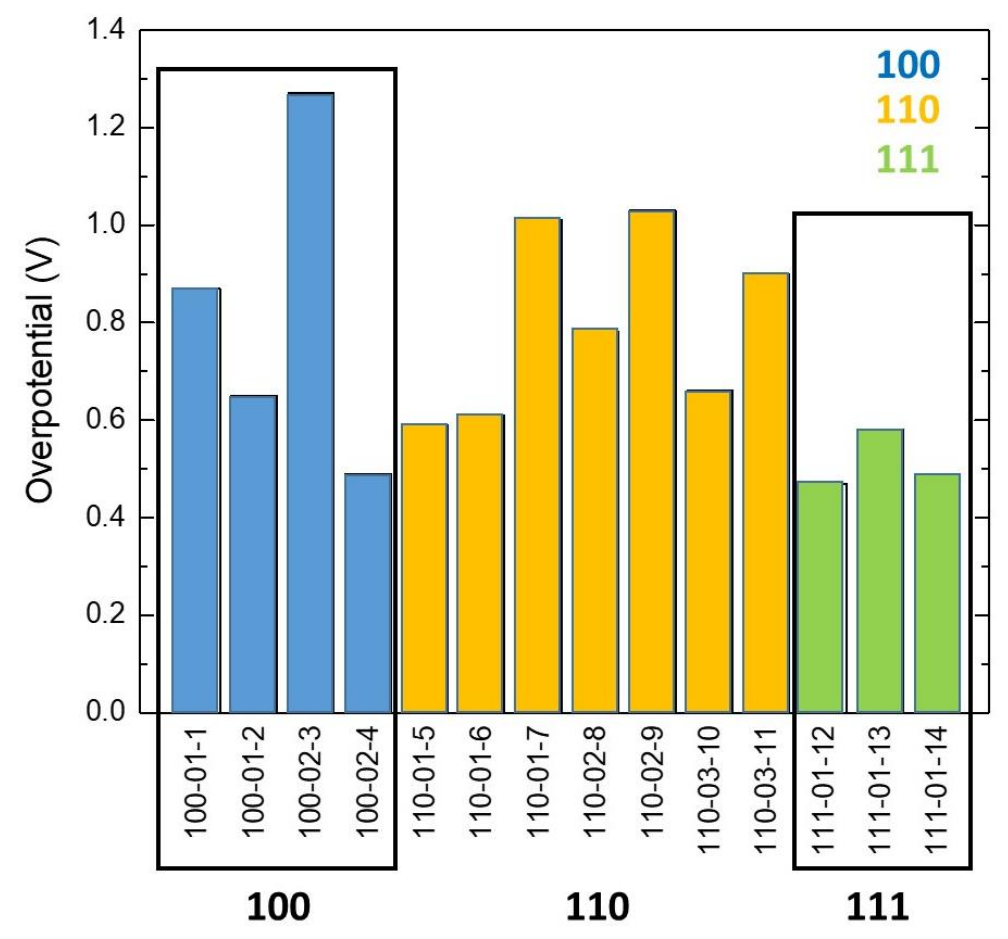

Figure 5: DFT calculated overpotentials of all 14 geometries. The different orientations are illustrated by different colors.

\section{Bader charge (BC) analysis}

To find a correlation between the overpotential, i.e. the electrochemical activity, structure and potential determining step, Bader charge analysis was carried out.

First, the Bader charges of the bulk $\mathrm{Ag}_{3} \mathrm{PO}_{4}$ were calculated. The Bader charge for $\mathrm{Ag}$ is 10.36 (average of three almost identical Ag), 1.38 for $\mathrm{P}$, and 7.38 for O. The electron transfer can be calculated with respect to the free valence charge, namely 11 for $\mathrm{Ag}, 5$ for $\mathrm{P}$ and 6 for $\mathrm{O}$. Comparing the free valence charge with the calculated Bader charge for the bulk, we conclude that there is net electron transfer from $\mathrm{Ag}$ and $\mathrm{P}$ atoms to $\mathrm{O}$ atoms. This results in a positive charge of 0.64 for $\mathrm{Ag}, 3.62$ for $\mathrm{P}$, and a negative charge of 1.38 for $\mathrm{O}$ in the bulk $\mathrm{Ag}_{3} \mathrm{PO}_{4}$. The Bader charge of bulk Ag was compared to the Bader charge of surface Ag as a function of the adsorbed species $\mathrm{HO}_{\mathrm{ad}}, \mathrm{O}_{\mathrm{ad}}$, and $\mathrm{HOO}_{\mathrm{ad}}$. No distinct correlation between the 14 different geometries and the Ag surfaces charges is found.

Therefore, the charges of the oxygen ions of all adsorbed species were calculated for all geometries. This data is summarized together with the overpotential data in Table $\mathrm{S} 1$ in the supporting information. It is found that the $\mathrm{BC}$ of the oxygen decreases from $\mathrm{HO}_{\mathrm{ad}}$ over $\mathrm{O}_{\mathrm{ad}}$ to $\mathrm{HOO}_{\mathrm{ad}}$ (refer to $\mathrm{BC}_{\mathrm{OH}}, \mathrm{BC}_{\mathrm{O}}$, and $\mathrm{BC}_{\mathrm{HOO}}$ ) which means that the $\mathrm{Ag}-\mathrm{O}$ bond strength reduces as the OER proceeds. This finding is valid for all geometries, except for the 100-02-3 geometry with the highest overpotential of $1.27 \mathrm{~V}$.

The calculated Bader charges of the oxygen can, however, not explain the different overpotentials for the different geometries. Therefore, the charge redistributions (CR) during the OER was calculated. We choose the $\mathrm{O}_{\mathrm{ad}}$ and $\mathrm{HOO}_{\mathrm{ad}}$ formation steps to study the charge 
redistribution because the formation of $\mathrm{O}_{\mathrm{ad}}$ or $\mathrm{HOO}_{\mathrm{ad}}$ is usually the potential determining step. The charge redistribution of the $\mathrm{O}_{\mathrm{ad}}$ formation step is calculated as $\mathrm{CR}_{\mathrm{O}}=\mathrm{BC}_{\mathrm{HO}}-\mathrm{BC}_{\mathrm{O}}$; the charge redistribution of the $\mathrm{HOO}_{\mathrm{ad}}$ formation step is calculated as $\mathrm{CR}_{\mathrm{HOO}}=\mathrm{BC}_{\mathrm{O}}-\mathrm{BC}_{\mathrm{HOO}}$. Figure 6 shows the difference in charge redistribution of the two steps, i.e. $\mathrm{CR}_{\mathrm{O}}-\mathrm{CR}_{\mathrm{HOO}}$, as a function of the OER overpotential for the two potential determining steps. The charge redistribution difference is about one order of magnitude higher for the $\mathrm{O}_{\mathrm{ad}}$ formation step (black squares) compared to the $\mathrm{HOO}_{\mathrm{ad}}$ formation step (red triangles). Hence, if CRo is much larger than $\mathrm{CR}_{\mathrm{HOO}}$, then the $\mathrm{O}_{\mathrm{ad}}$ formation is potential determining. If $\mathrm{CR}_{\mathrm{O}}$ and $\mathrm{CR}_{\mathrm{HOO}}$ are similar, i.e. small value of $\mathrm{CR}_{\mathrm{O}}-\mathrm{CR}_{\mathrm{HOO}}$, then the $\mathrm{HOO}_{\mathrm{ad}}$ formation is limiting.

For both rate determining steps, $\mathrm{CR}_{\mathrm{O}}-\mathrm{CR}_{\mathrm{HOO}}$ increases with increasing overpotential (illustrated by semi-transparent areas). Hence, we see a general trend: when the difference in charge redistribution of the subsequent $\mathrm{O}_{\mathrm{ad}}$ and $\mathrm{HOO}_{\mathrm{ad}}$ formation step is small (low value of $\mathrm{CR}_{\mathrm{O}}-\mathrm{CR}_{\mathrm{HOO}}$ ), the overpotential is small. This means that the overpotential is directly coupled to the amount of charge redistribution between two subsequent steps. If not much charge needs to be redistributed in subsequent steps, then the overpotential is small and the electrochemical activity of the surface is high.

This trend is in agreement with partial density of states (PDOS) analysis using 3 data sets (highlighted in Fig. 6 and DOS plots are shown in Fig. S2 in the supplement information). We observe that the first PDOS peak from below Fermi level (occupied states) for 111-01-12 (overpotential $=0.47 \mathrm{~V}$ ) shifts to above Fermi level (unoccupied states) for 110-02-8 (overpotential $=0.78 \mathrm{~V}$ ) and even further for 100-02-3 (overpotential $=1.27 \mathrm{~V}$ ). The more states above the Fermi level, the higher the overpotential. However, since DOS analysis mostly provide analysis qualitatively, it is challenging to justify the small differences found in other data sets, where the values of the overpotentials are very similar.

A design parameter to lower $\mathrm{CRO}$ - $\mathrm{CRHOO}$ could be the bonding strength of the adsorbed $\mathrm{O}$ to the adsorption site: If the $\mathrm{O}_{\mathrm{ad}}$ is relatively strongly bond to the $\mathrm{Ag}$ atoms of the $\mathrm{Ag}_{3} \mathrm{PO}_{4}$, the reactions of $\mathrm{OH}_{\mathrm{ad}}$ to $\mathrm{O}_{\mathrm{ad}}$ and then to $\mathrm{HOO}_{\mathrm{ad}}$ have small impact on the charge redistribution. If the $\mathrm{O}_{\mathrm{ad}}$ is, however, only weakly bond to the $\mathrm{Ag}$, the impact of the above reactions are more pronounced and CRO - CRHOO is believed to be larger. 


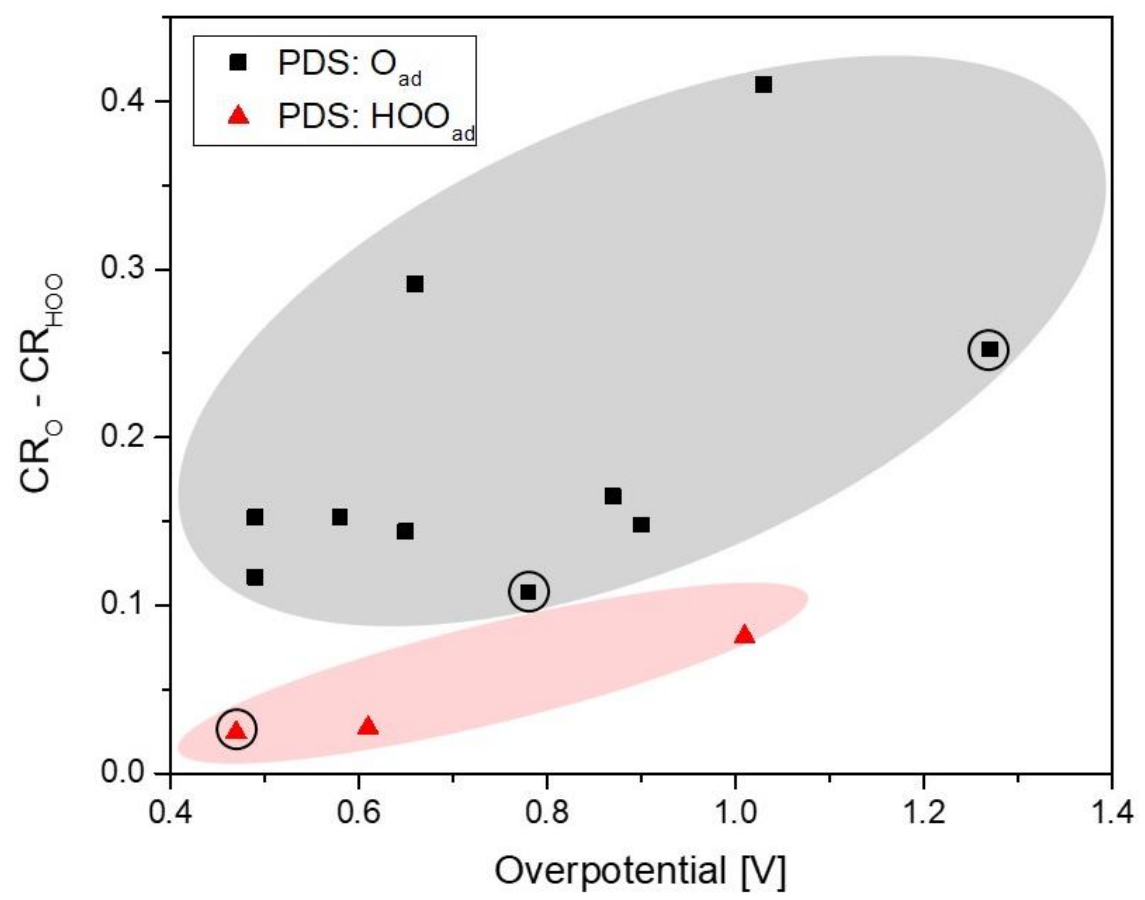

Figure 6. The difference in charge redistribution during the $O_{a d}$ and the $H O O_{a d}$ formation steps as a function of overpotential. The data is grouped according to the two potential determining steps (PDS), namely $O_{\text {ad }}$ formation and $\mathrm{OOH}_{\text {ad }}$ formation. The shadowed areas illustrate the increase of overpotential with increased difference in charge redistribution. Highlighted in circles are the data points analyzed by PDOS in Fig. S2 in the support information.

\section{Summary and Outlook}

We have investigated the structural sensitivity of the OERs on (100), (110), and (111) surfaces of $\mathrm{Ag}_{3} \mathrm{PO}_{4}$ through a systematic analysis of reaction energies and overpotentials using DFT. In all our studies, the intermediate species are adsorbed on the Ag site. Our results confirmed the high activity of the (111) surfaces with the lowest overpotential being $0.47 \mathrm{~V}$. This overpotential is similar to the overpotential of $\mathrm{RuO}_{2}(0.37 \mathrm{~V})$ whose OER activity is one of the lowest overpotentials known for OER ${ }^{[20]}$. The overpotentials of OERs on the (110) and the (100) surface are, in contrast, spread widely from $0.49 \mathrm{~V}$ to $1.27 \mathrm{~V}$. Most overpotentials ( 9 out of 11) are considerably higher than those on the (111) surfaces. This is in general in agreement with the literature ${ }^{[10,16]}$. We are aware that $\mathrm{P}$ adsorption sites and hydroxylated $\mathrm{P}$ atoms as well as the addition of explicit solvent might play an important role in the energies and kinetics of the OER on $\mathrm{Ag}_{3} \mathrm{PO}_{4}$; such effects remain to be addressed in future studies.

In our study, we went one step further in order to understand the reasons for the different overpotentials. We found that neither orientation nor the number of Ag atoms involved in the adsorption of the intermediate species nor the type of surface termination or the different potential determining reaction steps could unambiguously relate to the calculated overpotentials. Bader charge analysis finally revealed that charge redistribution during the OER is decisive for a low overpotential. If the difference in the charge redistribution between two consecutive steps, $\mathrm{O}_{\mathrm{ad}}$ formation and $\mathrm{OOH}_{\mathrm{ad}}$ formation $\left(\mathrm{CR}_{\mathrm{O}}-\mathrm{CR}_{\mathrm{HOO}}\right)$, is small, the overpotential is small; if it is high, the overpotential is high. This finding allows to relate the electrochemical activity, i.e. the 
overpotential, to the atomistic changes during OER. This concept of relating the charge redistribution during electrochemical reactions to the overpotential is new and is here for the first time established for the OER mechanism of $\mathrm{Ag}_{3} \mathrm{PO}_{4}$. It should be noted that several factors, such as the surface termination, the local structure and the surrounding, affect the results of the charge redistribution. Thus, the charge redistribution data is an overall result of interplay of several factors mention above. Investigation of other electrochemical mechanisms and interfaces in the future is necessary to establish how universal this new concept is..

\section{Acknowledgement}

Zhang, Sinha, and Bieberle-Hütter acknowledge the financial support from NWO (FOM program nr. 147 "CO2 neutral fuels"). Zhang also acknowledges funding from M-ERA.NET Call 2016 for the project "MuMo4PEC" with project number M-ERA.NET 4089. Tao acknowledge funding by the Computational Sciences for Energy Research (CSER) tenure track program of Shell, NWO, and FOM (Project number15CST04-2). The authors acknowledge Dr. Peter Klaver for technical support regarding VASP. Supercomputing facilities of the Dutch national supercomputers SURFsara/Lisa and Cartesius are acknowledged.

\section{References}

1 M. Grätzel, Nature, 2001, 414, 338-344.

2 A. Yilanci, I. Dincer and H. Ozturk, Prog. Energy Combust. Sci., 2009, 35, 231-244.

3 A. Valdés, J. Brillet, M. Grätzel, H. Gudmundsdóttir, H. A. Hansen, H. Jónsson, P. Klüpfel, G.-J. Kroes, F. L. Formal, I.C. Man, R. S. Martins, J. K. Nørskov, J. Rossmeisl, K. Sivula, A. Vojvodic and M. Zäch, Phys. Chem. Chem. Phys., 2012, 14, 49-70.

4 P. Liao, E. A. Carter, Chem. Soc. Rev, 2013, 42, 2401-2422.

5 A. V. Akimov, A. J. Neukirch and O. V. Prezhdo, Chem. Rev, 2013, 113, 4496-4565.

6 X. Yang, Z. Chen, J. Xu, H. Tang, K. Chen and Y. Jiang, ACS Appl. Mater. Interfaces, 2015, 7, $15285-15293$.

7 Z. Yi, J. Ye, N. Kikugawa, T. Kako, S. Ouyang, H. Stuart-Williams, H. Yang, J. Cao, W. Luo, Z. Li, Y. Liu and R. L. Withers, Nat.Mater., 2010, 9, 559-564.

8 H. Hu, Z. Jiao, H. Yu, G. Lu, J. Ye and Y. Bi, J. Mater. Chem. A, 2013, 1, 2387.

9 K. Tennakone, A. H. Jayatissa and W. Wijeratne, J. Chem. Soc., Chem. Commun., 1988, 496.

10 D. J. Martin, N. Umezawa, X. Chen, J. Ye and J. Tang, Energy Environ. Sci. 2013, 6, 3380.

11 B. Zheng, X. Wang, C. Liu, K. Tan, Z. Xie and L. Zheng, J. Mater. Chem. A, 2013, 1, 12635.

12 Y. Bi, S. Ouyang, N, Umezawa, J. Cao and J. Ye, J. Am. Chem. Soc., 2011, 133, 6490-6492.

13 X. Ma, J. Yan, N. Liu, L. Zhu, B. Wang, C. Huang and H. Lü, J. Semicond., 2016, 37, 033001.

14 J. M. Kahk, D. L. Sheridan, A. B. Kehoe, D. O. Scanlon, B. J. Morgan, G. W. Watson and D. J. Payne, J. Mater. Chem. A, 2014, 2, 6092-6099. 
15 J. J. Liu, X. L. Fu, S. F. Chen and Y. F. Zhu, Appl. Phys. Lett., 2011, 99, 191903.

16 Z. Ma, S. Lin, R. Sa, Q. Li and K. Wu, RSC Adv., 2017, 7, 23994-24003

17 V. Fidelsky and M. C. Toroker, J. Phys. Chem. C., 2016, 120, 8104-8108.

18 S. Yang, D. Prendergast and J. B. Neaton, Nano Lett., 2011, 12, 383-388.

19 X. Zhang and A. Bieberle-Hütter, ChemSusChem 2016, 9, 1223 - 1242.

20 J. Rossmeisl, Z.-W. Qu, H. Zhu, G.-J. Kroes and J. Nørskov, J. Electroanal. Chem., 2007, 607, 83-89.

21 O. Neufeld and M. C. Toroker, J. Phys. Chem. C, 2015, 119, 5836-5847.

22 X. Zhang, P. Klaver, R. A. van Santen, M. C. M. Van De Sanden and A. Bieberle-Hütter, J. Phys. Chem. C, 2016, 120, 18201-18208.

23 R. Frydendal, M. Busch, N. B. Halck, E. A. Paoli, P. Krtil, I. Chorkendorff and J. Rossmeisl, ChemCatChem, 2014, 7, 149-154.

24 F. Calle-Vallejo, O. A. Díaz-Morales, M. J. Kolb and M. T. M. Koper, ACS Catal., 2015, 5, 869-873.

25 J. Yang, H. An, X. Zhou and C. Li, J. Phys. Chem. C, 2015, 119, 18487-18494

26 X. Zhang, C. Cao and A. Bieberle-Hütter, J. Phys. Chem. C, 2016, 120, 28694-28700.

27 X. Zhou, E. J. Hensen, R. A. van Santen, C. Li, Chem. Eur. J., 2014, 20, 6915-6926.

28 A. Hellman, B. Iandolo, B. Wickman, H. Grönbeck and J. Baltrusaitis, Surf. Sci., 2015, 640, 45-49.

29 M.-T. Nguyen, S. Piccinin, N. Seriani and R. Gebauer, ACS Catal., 2014, 5, 715-721.

30 F.M. Sapountzi , J.M. Gracia , C.J. Weststrate, H.O.A. Fredriksson, J.W. Niemantsverdriet, Progress in Energy and Combustion Science 58 (2017) 1-35.

[31] Z. Zhang, X. Wang, G. Cui, A. Zhang, X. Zhou, H. Xu and L. Gu, Nanoscale, 2014,6, 3540-3544.

32 P. Liao, J. A. Keith and E. A. Carter, J. Am. Chem. Soc., 2012, 134, 13296-13309.

33 D. K. Kanan, J. A. Keith and E. A. Carter, ChemElectroChem, 2014, 1, 407-415.

34 G. Kresse and D. Joubert, Phys. Rev. B, 1999, 59, 1758-1775.

35 G. Kresse and J. Furthmüller, Comput. Mater. Sci., 1996, 6, 15-50.

36 P .E. Blöchl, Phys. Rev. B, 1994, 50, 17953.

37 J. P. Perdew, K. Burke, and M. Ernzerhof, Phys. Rev. Lett., 1996, 77, 3865.

38 H. N. Ng, C. Calvo and R. Faggiani, Acta Crystallogr, 1978, 34, 898-899.

39 W. Tang, E. Sanville and G. Henkelman, J. Phys.: Condens. Matter, 2009, 21, 084204. 
40 G. Henkelman, A. Arnaldsson and H. Jónsson, Comput. Mater. Sci., 2006, 36, 354-360.

41 S. Piccinin and S. Fabris, Inorganics, 2015, 3, 374-387. 